Nepal

\title{
Nishant Thakur
}

Ministry of Health and Population, Nepal

\section{Avinash K Sunny}

Golden Community

\section{Rejina Gurung}

Golden Community

\section{Omkar Basnet}

Gateway Community

\section{Helena Litorp}

Uppsala Universitet

Ashish KC ( $\square$ aaashis7@yahoo.com)

Uppsala Universitet https://orcid.org/0000-0002-0541-4486

\section{Research}

Keywords: Instrument assisted vaginal birth, Risk factors, Neonatal outcomes, Nepal

Posted Date: April 29th, 2020

DOI: https://doi.org/10.21203/rs.3.rs-23838/v1

License: (9) (i) This work is licensed under a Creative Commons Attribution 4.0 International License. Read Full License 


\section{Abstract}

Background Instrument assisted vaginal birth (IVB) is an effective intervention for deliveries complicated by prolonged labour or fetal distress, but its use is declining in many low-resource settings. In this paper, we examined intra-hospital rates of IVB, factors associated, and neonatal outcomes after IVB in Nepal.

Methods This is a prospective cohort study of all deliveries conducted in 12 public hospitals ( 4 high volume, 4 medium volume and 4 low volume) across Nepal for 18 months. We calculated the rate of IVB and used logistic regression to assess the association between IVB and neonatal morbidity (Apgar score $<7$ at 5 minutes, shoulder dystocia) and mortality.

Results A total of 81,581 deliveries were included in the study, of which 3001 (3.4\%) were IVBs., while rates in high volume, medium volume, and small volume hospitals were $3.6 \%, 3.7 \%$ and $1.2 \%$ respectively. The odds of Apgar score $<7$ at 5 minutes was almost three-fold (aOR 2.92, 95\% Cl, 2.493.42) with IVB compared to spontaneous vaginal birth (SVB). The odds of shoulder dystocia was threefold (aOR 3.04, 95\% Cl, 2.19-4.22) with IVB compared to SVB. The odds of first day mortality was lower in medium volume (aOR-0.57, $95 \% \mathrm{Cl}, 0.42-0.78)$ hospitals compared to high volume hospitals.

Conclusions The rate of IVB varied by volume of hospital. The neonatal outcome were poor among the babies born to IVB, and neonatal outcomes were worse after IVB at high-volume hospitals. Further studies to explore factors determining the rate of IVB and better neonatal outcomes.

\section{Plain English Summary}

Complication during labour and birth is a leading cause of neonatal and maternal deaths globally, accounting for 2.4 million deaths annually. Instrument assisted birth (IVB) has been practiced for several decades as a safe intervention for high risk birth. This study was done to assess the rate of instrument assisted birth (IVB) and birth outcome.

The study was conducted in 12 public hospitals in Nepal for a period of 18 months. Hospitals was categorized into high, medium and low volume based on annual deliveries. High volume hospitals had more than 8000 annual deliveries, medium volume had 3000-8000 annual deliveries and low volume had 1000-3000 deliveries a year. Women who did not have elective cesarean section were excluded in this study.

The overall rate of instrumental delivery was $3.4 \%$, while rates in high volume, medium volume, and small volume hospitals were $3.6 \%, 3.7 \%$ and $1.2 \%$ respectively. The rate of IVB was higher among women who had agumentation of labour than those who did not. The rate of IVB was higher with babies birth weight 4000 gram or more other birth weight.

The risk of birth asphyxia and shoulder dystocia was higher IVB in reference to Sponateous vaginal birth. The babies born to IVB had poor neonatal outcome in high volume hospital than in medium volume 
hospital.

\section{Introduction}

In the last two decades, maternal and neonatal mortality has reduced globally by almost half and in Nepal by two thirds $[1,2]$. Yet, intrapartum complications remain a leading cause of neonatal and maternal deaths globally, accounting for 2.4 million deaths annually[3]. Instrument assisted delivery (IVB) has been practiced for several decades as a safe intervention for high risk pregnancies[4]. The choice instrument for vaginal birth is determined by the women and fetal condition and competence of health workers[5]. The decision for IVB depends on weighing-up its risk and benefit to perform it[6].

In Nepal hospital provide basic emergency and obstetric newborn care (BEmONC), which manages complications related to pregnancy and deliveries[7] where obstetricians, midwives and auxiliary midwives can perform instrumental deliveries including through the use of vacuums and forceps[8]. In the past two decades, there has been a declining trend of instrumental deliveries in the past two decades[5]. This is shown by less numbers of obstetricians and birthing staffs willing to perform instrumental deliveries, globally[9]. However, it is difficult to determing the trend of IVB use as there is very scarce reporting on the trend across birthing facilities in low resource settings such as Nepal[10].

In order to address this evidence gap, this paper explores the rate and neonatal outcomes of instrumental deliveries across 12 public hospitals in Nepal. Specifically, this paper will focus on comparing birth outcomes between 1) women who underwent instrumental deliveries, emergency caesarean sections, and spontaneous vaginal deliveries, and 2) women who underwent instrumental delivery in high-volume, medium-volume, and low-volume hospitals.

\section{Material And Methods}

\section{Design}

This is an prospective cohort study conducted in 12 public hospitals in Nepal for a period of 18 months (July 2017-November 2018) nested within a trial evaluating the scale-up of a quality improvement package for neonatal care; the Nepal Perinatal Quality Improvement Project (NePeriQIP) [11, 12]. In this study, 12 hospitals were included with a total of more than 100,000 deliveries during the study period[12]. All hospitals provided comprehensive emergency obstetric and neonatal care and had obstetricians assisting caesarean births and nurse-midwives trained in instrumental delivery[12]. Instrumental deliveries were performed as part of basic emergency obstetric care in all hospitals by trained health staff[13]. Labor units in all the hospitals are managed by skilled birth attendants .

The hospitals differed widely in relation to geography and the populations they serve with varying ethnicity, language, religion, service coverage and governance. Hospitals were categorized into high, medium and low volume based on annual deliveries. High volume hospitals had more than 8000 annual deliveries, medium volume had 3000-8000 annual deliveries and low volume had 1000-3000 deliveries a 
year. Within high volume hospitals (Koshi, Bharatpur, Lumbini and Pokhara) the annual birth ranged from 8050 to 14,000 in each hospital. Within medium volume hospitals (Seti, Surkhet, Bheri and Dang) the annual births ranged from 3100 to 7850 in each hospital. Within low volume hospitals (Nuwakot, Pyuthan, Nawalparasi and Bardiya) ranged from 1030 to 2410 in each hospital.

\section{Participants}

All participants registered in the NePeriQIP registry were eligible for the study. Women who did not have elective cesarean section were excluded in this study.

\section{Data collection and management}

Data was extracted from the NePeriQIP surveillance system that was established across the hospitals and gathered information from medical records and registries[11]. Health and demographic data of the mother was extracted from maternal registries and information about the babies were extracted form separate follow up forms. Data quality was managed and ensured by a data manager. Census and Survey Processing System (CSPro) was used for data processing.

\section{Variable and outcomes}

Primary outcome variable were rates of instrumental deliveries and Emergency caesarean section;

Secondary outcome variables were apgar score recorded at 5 minutes (method for reporting the status of the newborn infant immediately after birth and the response to resuscitation if needed) (less than 7 at 5 minutes indicate those requiring resuscitation), babies requiring bag and mask ventilation, birth asphyxia diagnosed in sick newborn care units (SNCU), shoulder dystocia, first day mortality and newborns requiring to transfer to SNCU;

Demographic characteristics include maternal age, ethnicity and maternal education;

Obstetric characteristics include multiple delivery, parity, gestational age, induction of labour (with prostaglandin, oxytocin and amniotomy) and augmentation of labour and neonatal characteristics include birth weight (supplementary table 1).

\section{Statistical analysis}

Descriptive statistics are presented using frequency tables and bar diagrams. For inferential statistics and odds ratios, binary logistic regression was used to compare outcomes related to (i) mode of delivery and (ii) IVB by volumes of hospitals. Multivariate logistic regressions was used to calculate adjusted odds ratios for various perinatal outcomes with demographic, obstetric and neonatal characteristics. Pvalue less than 0.05 was considered statistically significant. Variables with $p$ value $<0.2$ was considered 
for multivariate logistic regression. Missing data were excluded from the analysis. All data were analyzed using SPSS ver 20.

\section{Results}

During the study period, 104,223 admission took place in the hospitals of which 87,284 deliveries were recorded. Among these, 5703 elective caesarean sections were excluded from the study, leaving 81,581 deliveries (spontaneous vaginal deliveries $(64,846)$, instrumental deliveries $(3001)$, and emergency caesearan sections $(13,734)$ eligible for inclusion (Figure 1).

\section{Rates of instrumental deliveries}

The overall rate of instrumental delivery was $3.4 \%$, while rates in high volume, medium volume, and small volume hospitals were $3.6 \%, 3.7 \%$ and $1.2 \%$ respectively. Among the high volume hospitals, the rate was highest in Lumbini Zonal Hospital (5.7\%). Among the medium volume hospitals, the rate was highest in Bheri Zonal Hospital (4.2\%). Among the small volume hospitals, rates was high in Nuwakot district hospital (2.7\%) (Figure 2).

\section{Demographic, obstetric and neonatal characteristics by mode of delivery}

The rate of IVB was higher among primiparous women $(5.1 \%, 95 \% \mathrm{Cl}, 4.9-5.4)$ than others. The rate of IVB was higher among women who had agumentation of labour $(6.5 \%, 95 \% \mathrm{Cl}, 6.2-6.8)$ than those who did not $(2.1 \%, 95 \% \mathrm{Cl}, 1.9-2.2)$. The rate of IVB was higher with babies birth weight 4000 gram or more $(5.9 \%, 95 \% \mathrm{Cl}, 4.8-7.2)$ other birth weight. The rate of IVB was higher with gestational age 41 weeks or more $(5.0 \%, 95 \% \mathrm{Cl}, 4.2-5.9)$ other gestational age (Table 1$)$. 
Table 1

Mode of delivery among women with different maternal and obstetric characteristics at 12 public hospitals in Nepal $(\mathbf{N}=\mathbf{8 1}, \mathbf{5 8 1})$.

\begin{tabular}{|c|c|c|c|}
\hline & Vaginal & Instrumental & Emergency c-section \\
\hline \multicolumn{4}{|l|}{ Maternal_age (N-81,581) } \\
\hline $20-35$ yrs (n-60,198) & $78.8 \%(78.4-79.1)$ & $3.7 \%(3.5-3.8)$ & $17.5 \%(17.2-17.8)$ \\
\hline$<20$ yrs (n-20427) & $82.1 \%(81.6-82.6)$ & $3.6 \%(3.4-3.9)$ & $14.3 \%(13.8-14.8)$ \\
\hline >35 yrs (n-956) & $69.1 \%(66.1-72.0)$ & $3.7 \%(2.6-5.1)$ & $27.2 \%(24.5-30.1)$ \\
\hline \multicolumn{4}{|l|}{ Parity } \\
\hline Nulliparity (n-27,683) & $83.1 \%(82.6-83.5)$ & $2.4 \%(2.2-2.6)$ & $14.5 \%(14.1-14.9)$ \\
\hline Primiparity (n-38,553) & 76.7 \% (76.3-77.1) & $5.1 \%(4.9-5.4)$ & 18.1 \% (17.8-18.5) \\
\hline Multiparity (n-15337) & $80.0 \%(79.3-80.6)$ & $2.3 \%(2.1-2.6)$ & 17.7 \% (17.1-18.3) \\
\hline \multicolumn{4}{|l|}{ *missing-8 } \\
\hline \multicolumn{4}{|l|}{ Ethnicity (N-81581) } \\
\hline Advantaged $(n-41,152)$ & $80.0 \%(79.6-80.4)$ & $3.7 \%(3.5-3.9)$ & $16.4 \%(16.0-16.7)$ \\
\hline Disadvantaged $(\mathrm{n}-40,429)$ & 79.0\% (78.6-79.4) & $3.7 \%(3.5-3.9)$ & $17.3 \%(17.0-17.7)$ \\
\hline \multicolumn{4}{|l|}{ Literacy (N-62600) } \\
\hline Literate (n-59,676) & $80.8 \%(80.5-81.1)$ & $3.8 \%(3.7-4.0)$ & $15.3 \%(15.0-15.6)$ \\
\hline Illiterate (n-2924) & $81.3 \%(79.8-82.7)$ & $3.6 \%(3.0-4.3)$ & $15.1 \%(13.9-16.5)$ \\
\hline \multicolumn{4}{|l|}{ Induction of labour- 72657} \\
\hline No $(n-49,092)$ & $81.5 \%(81.2-81.8)$ & $3.6 \%(3.4-3.8)$ & $14.9 \%(14.6-15.2)$ \\
\hline Prostaglandin $(n-14,386)$ & $77.5 \%(76.8-78.1)$ & $4.3 \%(3.9-4.6)$ & $18.3 \%(17.7-18.9)$ \\
\hline Amniotomy (n-1,888) & $81.5 \%(79.6-83.2)$ & $3.3 \%(2.6-4.2)$ & $15.2 \%(13.7-16.9)$ \\
\hline Oxytocin (n-7,291) & $82.1 \%(81.2-83.0)$ & $4.0 \%(3.6-4.5)$ & $13.9 \%(13.1-14.7)$ \\
\hline \multicolumn{4}{|l|}{ *missing-8,924 } \\
\hline \multicolumn{4}{|l|}{ Agumentation (N-77,313) } \\
\hline No $(n-47,897)$ & $79.2 \%(78.9-79.6)$ & $2.1 \%(1.9-2.2)$ & $18.7 \%(18.4-19.1)$ \\
\hline Yes $(n-29,416)$ & $81.0 \%(80.5-81.4)$ & $6.5 \%(6.2-6.8)$ & $12.5 \%(12.2-12.9)$ \\
\hline
\end{tabular}




\begin{tabular}{|llll|}
\hline Gestational age (N-75,834) & & & \\
\hline $37-41$ wks $(\mathrm{n}-51,991)$ & $78.8 \%(78.5-79.2)$ & $3.8 \%(3.7-4.0)$ & $17.3 \%(17.0-17.7)$ \\
\hline$<37$ wks $(\mathrm{n}-21,424)$ & $82.2 \%(81.7-82.7)$ & $2.8 \%(2.6-3.1)$ & $15.0 \%(14.5-15.4)$ \\
\hline$>41$ wks $(\mathrm{n}-2,419)$ & $75.4 \%(73.6-77.1)$ & $5.0 \%(4.2-5.9)$ & $19.6 \%(18.1-21.3)$ \\
\hline Twin $(\mathrm{N}-81,581)$ & & & \\
\hline No (n-80,730) & $79.6 \%(79.3-79.9)$ & $3.7 \%(3.6-3.8)$ & $16.7 \%(16.4-16.9)$ \\
\hline Yes (n-851) & $66.0 \%(62.8-69.1)$ & $3.3 \%(2.3-4.7)$ & $30.7 \%(27.7-33.9)$ \\
\hline Birth weight (N-75,835) & & & \\
\hline $2500-3999(n-60,381)$ & $79.7 \%(79.4-80.0)$ & $3.8 \%(3.7-4.0)$ & $16.5 \%(16.2-16.8)$ \\
\hline$<2500(n-13,953)$ & $82.1 \%(81.4-82.7)$ & $2.3 \%(2.1-2.6)$ & $15.6 \%(15.0-16.2)$ \\
\hline$>4000(n-1501)$ & $57.1 \%(54.6-59.6)$ & $5.9 \%(4.8-7.2)$ & $37.0 \%(34.6-39.5)$ \\
\hline *missing-5746 & & & \\
\hline
\end{tabular}

\section{Birth outcomes following IVB}

Birth outcomes among deliveries following spontaneous vaginal birth, IVB and emergency cesarean section (CS) are described in Table 2 and 3. Rates of babies with Apgar $<7$ at $5 \mathrm{~min}(9 \%$ ), birth asphyxia ( $2 \%)$, shoulder dystocia (3.6\%), first day mortality $(0.2 \%)$ and babies requiring transfer to SNCU $(5.2 \%)$ were found to be higher following IVB as compared to both spontaneous vaginal birth and caesarean section. 
Table 2

Neonatal outcomes among deliveries with spontaneous vaginal delivery (SVB), instrumental vaginal birth (IVB) , and caesarean section (CS) at 12 hospitals in Nepal. Spontaneous vaginal delivery represents OR 1.0. (Statistically significant results in the multi-variate analyses is indicated with *).

\begin{tabular}{|c|c|c|c|c|c|c|c|}
\hline \multirow[t]{2}{*}{ Outcome } & \multirow{2}{*}{$\begin{array}{l}\text { SVB } \\
\text { (ref) }\end{array}$} & \multirow{2}{*}{$\begin{array}{l}\text { Instrumental } \\
\text { delivery }\end{array}$} & \multirow{2}{*}{$\begin{array}{l}\text { Emergency } \\
\text { CS }\end{array}$} & \multicolumn{3}{|c|}{ Instrumental delivery } & Emergency CS \\
\hline & & & & $\mathrm{cOR}$ & $\mathrm{aOR}$ & $\mathrm{cOR}$ & $\mathrm{aOR}$ \\
\hline $\begin{array}{l}\text { Apgar }<7 \text { at } \\
5 \mathrm{~min}\end{array}$ & $2,616(4 \%)$ & $270(9 \%)$ & $545(4 \%)$ & $\begin{array}{l}2.35 \\
(2.06- \\
2.68)\end{array}$ & $\begin{array}{l}2.92^{\star} \\
(2.49- \\
3.42)\end{array}$ & $\begin{array}{l}0.98 \\
(0.89- \\
1.08)\end{array}$ & $\begin{array}{l}1.06(0.93- \\
1.91)\end{array}$ \\
\hline $\begin{array}{l}\text { Birth } \\
\text { asphyxia }\end{array}$ & $290(0.4 \%)$ & $59(2.0 \%)$ & $108(0.8 \%)$ & $\begin{array}{l}4.46 \\
(3.37- \\
5.92)\end{array}$ & $\begin{array}{l}4.09 * \\
(2.54- \\
6.60)\end{array}$ & $\begin{array}{l}1.76 \\
(1.41- \\
2.20)\end{array}$ & $\begin{array}{l}0.92(0.58- \\
1.47)\end{array}$ \\
\hline $\begin{array}{l}\text { Shoulder } \\
\text { dystocia }\end{array}$ & $816(1.3 \%)$ & $107(3.6 \%)$ & $371(2.7 \%)$ & $\begin{array}{l}2.90 \\
(2.36- \\
3.56)\end{array}$ & $\begin{array}{l}3.04^{\star} \\
(2.19- \\
4.22)\end{array}$ & - & - \\
\hline $\begin{array}{l}\text { Transferred } \\
\text { to SNCU }\end{array}$ & $1074(1.7 \%)$ & $156(5.2 \%)$ & $493(3.6 \%)$ & $\begin{array}{l}3.25 \\
(2.74- \\
3.87)\end{array}$ & $\begin{array}{l}3.23^{\star} \\
(2.56- \\
4.07)\end{array}$ & $\begin{array}{l}2.21 \\
(1.98- \\
2.46)\end{array}$ & $\begin{array}{l}1.10(0.91- \\
1.34)\end{array}$ \\
\hline $\begin{array}{l}\text { First-day } \\
\text { mortality }\end{array}$ & $248(0.4 \%)$ & $7(0.2 \%)$ & $29(0.2 \%)$ & $\begin{array}{l}0.61 \\
(0.29- \\
1.29)\end{array}$ & $\begin{array}{l}1.07 \\
(0.47- \\
2.45)\end{array}$ & $\begin{array}{l}0.55 \\
(0.37- \\
0.81)\end{array}$ & $\begin{array}{l}0.62^{\star} \\
(0.39-0.98)\end{array}$ \\
\hline
\end{tabular}

aOR- Adjusted for Maternal age , Parity (ref-multipara), Gestational age, Birth weight, Induction of labor, and Augmentation labor

Risks for various birthing outcomes were analyzed using a regression analysis after adjusting for demographic and obstetrical factors such as maternal age, parity, gestational age, birth weight, induction of labor and augmentation. The odds of babies to be born with Apgar $<7$ at 5 minutes was two-fold $s$ in IVB(aOR-2.92, 95\% Cl, 2.49-3.42) in reference to spontaneous vaginal birth (SVB). There was no significant odds for babies born with Apgar $<7$ at 5 minutes through emergency c-section (aOR-1.06, 95\% $\mathrm{Cl}, 0.93-1.91)$ in reference to SVB. The odds of birth asphyxia was fourfold higher IVB (aOR-4.09, $95 \% \mathrm{Cl}$, 2.54-6.60) in reference to SVB. There was no significiant odds of birth asphyxia in babies born to emergency CS (aOR-0.92, 95\% Cl, 0.58-1.47) in reference to SVB. compared to CS births and SVD. The odds of shoulder dystocia was three-fold higher for babies born to IVB aOR-3.04, 95\% Cl, 2.19-4.22) than in referrence to SVB. The odds of baby for being transferred to specialized newbon care unit was threefold higher for babies born to IVB (aOR-3.23, 95\% Cl, 2.56-4.07) in reference to SVB. (Table 3). 
Table 3

Neonatal outcomes after instrumental delivery in high volume, medium volume and low volume hospitals. High volume hospitals represent OR 1.0. (Statistically significant results in the multi-variate analyses are indicated with *).

\begin{tabular}{|c|c|c|c|c|c|c|c|}
\hline \multirow[t]{2}{*}{ Outcome } & \multirow[t]{2}{*}{$\begin{array}{l}\text { High volume } \\
\text { hospitals(ref) }\end{array}$} & \multirow{2}{*}{$\begin{array}{l}\text { Medium } \\
\text { volume } \\
\text { hospitals }\end{array}$} & \multirow{2}{*}{$\begin{array}{l}\text { Low } \\
\text { volume } \\
\text { hospitals }\end{array}$} & \multicolumn{2}{|c|}{$\begin{array}{l}\text { Medium volume } \\
\text { hospitals }\end{array}$} & \multicolumn{2}{|c|}{$\begin{array}{l}\text { Low volume } \\
\text { hospitals }\end{array}$} \\
\hline & & & & $\begin{array}{l}\mathrm{COR} \\
(95 \% \mathrm{Cl})\end{array}$ & $\mathrm{aOR}$ & $\mathrm{cOR}$ & $\mathrm{aOR}$ \\
\hline Apgar<7@5min & $173(10.1 \%)$ & $94(7.8 \%)$ & $3(3.8 \%)$ & $\begin{array}{l}0.76 \\
(0.71- \\
0.82)\end{array}$ & $\begin{array}{l}0.66^{\star} \\
(0.61- \\
0.73)\end{array}$ & $\begin{array}{l}0.59 \\
(0.51- \\
0.68)\end{array}$ & $\begin{array}{l}0.42^{\star} \\
(0.34- \\
0.52)\end{array}$ \\
\hline Birth asphyxia & $25(1.5 \%)$ & $34(2.8 \%)$ & $0(0 \%)$ & $\begin{array}{l}1.96 \\
(1.63- \\
2.35)\end{array}$ & $\begin{array}{l}0.65^{\star} \\
(0.47- \\
0.89)\end{array}$ & $\begin{array}{l}0.79 \\
(0.51- \\
1.23)\end{array}$ & $\begin{array}{l}0.44^{*} \\
(0.21- \\
0.91)\end{array}$ \\
\hline $\begin{array}{l}\text { Shoulder } \\
\text { dystocia }\end{array}$ & $51(3.0 \%)$ & $54(4.5 \%)$ & $2(2.5 \%)$ & $\begin{array}{l}1.90 \\
(1.71- \\
2.12)\end{array}$ & $\begin{array}{l}0.73^{\star} \\
(0.60- \\
0.89)\end{array}$ & $\begin{array}{l}1.13 \\
(0.91- \\
1.42)\end{array}$ & $\begin{array}{l}0.39 \\
(0.24- \\
0.64)\end{array}$ \\
\hline $\begin{array}{l}\text { Transferred to } \\
\text { SNCU }\end{array}$ & $96(5.6 \%)$ & $59(4.9 \%)$ & $1(1.3 \%)$ & $\begin{array}{l}0.92 \\
(0.83- \\
1.00)\end{array}$ & $\begin{array}{l}0.39 * \\
(0.33- \\
0.46)\end{array}$ & $\begin{array}{l}0.37 \\
(0.28- \\
0.49)\end{array}$ & $\begin{array}{l}0.39 * \\
(0.29- \\
0.54)\end{array}$ \\
\hline $\begin{array}{l}\text { First-day } \\
\text { mortality }\end{array}$ & $4(0.2 \%)$ & $3(0.2 \%)$ & $0(0 \%)$ & $\begin{array}{l}0.72 \\
(0.56- \\
0.92)\end{array}$ & $\begin{array}{l}0.57 * \\
(0.42- \\
0.78)\end{array}$ & $\begin{array}{l}0.84 \\
(0.54- \\
1.30)\end{array}$ & $\begin{array}{l}0.59 \\
(0.35- \\
1.01)\end{array}$ \\
\hline
\end{tabular}

aOR- Adjusted for Maternal age, Parity, Gestational age, Birth weight, Induction of labor, and Augmentation labor

Table 3 describes neonatal outcomes following IVB in different hospital volumes. Rates of low Apgar ( $<7$ at 5 mins) (10.1\%), babies requiring bag and mask ventilation (8.8\%), and those requiring transfer to SNCU (5.6\%) after IVB was higher in high volume hospitals. However, occurrence of birth asphyxia (2.8\%) and rates of shoulder dystocia (4.5\%) was higher in medium volume hospitals following IVB. Regression analysis was used for various odds following IVB in medium and small volume hospital compared to high volume hospitals. The odds of low Apgar score following IVB was lower in medium (aOR-0.66, 95\% Cl, 0.61-0.73) and low volume hospitals (aOR-0.42, 95\% Cl, 0.34-0.52). The odds of birth asphyxia to babies born to IVB was lower in medium (aOR-0.65, 95\% $\mathrm{Cl}, 0.47-0.89$ ) and low volume (aOR$0.44,95 \% \mathrm{Cl}, 0.21-0.91)$ hospitals. The odds of shoulder dystocia, was lower in medium volume hospitals (aOR-0.73, 95\% Cl, 0.60-0.89) and low volume (aOR-0.39, 95\% Cl, 0.24-0.64) compared to high volume hospitals. The odds of first day mortality was lower in medium volume (aOR-0.57, 95\% Cl, 0.42-0.78) hospitals compared to high volume hospitals.

\section{Discussion}


From the study of 81,581 deliveries across 12 hospitals across Nepal, the overall rate of instrumental deliveries was found to be lower compared to CS births and SVB. This findings is similar to many studies in low resource setting hospitals in South-asia[14].

The rate of IVB was higher in medium volume hospitals compared to other hospitals. These hospitals are located in disadvantaged western regions in Nepal and face challenges such as the lack of skilled birth attendants and equipment for operative delivery[11]. Nepal's health facility survey 2015 also points to challenges in supporting IVB due to the lack of IVB equipment in delivery centers across country. Furthermore, rates of IVB is associated with skills of nurses and doctors on IVB. Mode of delivery depends on several factors like parity, obstetrical complication and presence of operative services in many settings $[15,16]$. Though primiparity is the highest risks factor for IVB success so as to avoid exhaustion faced by mother if SVB is done[17].

Skilled birth attendant in all settings are trained to perform IVB, however, when it comes to multiple delivery, caesarean section is opted as choice of delivery[18]. This is done to avoid failed instrumentation[19]. IVB and emergency CS is initiated when vaginal delivery is not successful 24 hours after induction of labour. Rates of CS is higher compared to IVB in births where an amniotomy was performed as a result of failed induction that is also seen in our study[20, 21].

Augmentation of labor with oxytocin has been indicated for prolonged labor (active phase of labor $>20$ hours in nulliparous and $>14$ hours in multiparous) [21]. However, failure to further of progress in labor after augumentation with oxytocin, IVB is initiated. This may be the explanation for the difference in rates of IVB in augmented and non-augmented groups. Instrumental deliveries are used with caution in gestation of less than 36 weeks, as it my cause intra-cranial injuries, so IVB is used in post-term pregnanacies[17]. In condition of large sized babies causing obstructed labour, birth resulting from IVB can have poor fetal outcome such as shoulder dystocia[22].

Outcomes vary following instrumental deliveries. Rates of poor neonatal outcomes were higher in IVB when compared to SVB and emergency CS. Babies born with IVB had poor Apgar at $5 \mathrm{~min}$. Similarly, odds of birth asphyxia [23], shoulder dystocia and transfer to SNCU was higher in IVB. This may be due to the lack of trained practitioners in Nepal to undertake instrumental deliveries in public hospitals in Nepal. Evidence has shown that training for IVB has reduced dramatically in many countries over the years[6].

The difference in results of APGAR score and birth asphyxia can be due to related to the method by which the outcomes are recorded. For example, APGAR scores are often recorded by the delivery staff in delivery rooms with poor lighting where staff are managing multiple priorities, while asphyxia is diagnosed by the clinicians using multiple criteria.

Findings showed higher odds of birth asphyxia and transferring newborn to sick newborn care unites, which is similar to study in South-east Nigeria[24]. Similarly, IVB is done for was more likely to cause shoulder dystocia. This may be linked to the size baby and high oxytocin augmentation. 
High volume hospitals are the referral centers which accommodate high risk cases. This could expain the high rate of neonatal complications. Additionally, possible cause could be inadequate nurses who are not trained and confident to conduct IVB and obstetrician preference to perform caesarean section in high volume hospitals.

\section{Methodological consideration}

One strength of this study was the large sample size of 87,248 deliveries for a period of 18 months from 12 hospitals from a wide geographical scope of the country, making it more generalizable.

The limitation of study was not being able to include all obstetrical factors and outcome as data were extracted from the patient case note (registry based). The inadequate use of patient case note might have led to poor reporting on obstetrical trauma and fetal injuries.

\section{Conclusions}

Instrumental deliveries is an effective intervention for managing complicated birth and reducing unnecessary use of caesarean birth. This study found that the overall rate of instrumental vaginal birth in Nepal is low and varied by the volume of the annual birth in the hospital. IVB has significant risks associated with poor fetal outcome such as sholder dystocia, birth asphyxia and mortality (mortality and morbidity) in these settings. The poor fetal outcome with IVB is also associated with the volume of annual birth in the hospital. Therefore, there is an urgent need to improve the hospital readiness and competency to increase the use of IVB and reduce indiscriminate use of CS as options for high risk deliveries.

\section{Abbreviation}

CS- cesarean section, IVB-Instrumental vaginal birth, SNCU- Sick newborn care unit, SVB-Spontaneous vaginal delivery

\section{Declarations}

Ethics Approval and Consent to Participate

The ethical approval for the study was taken from the Ethical Review Board (ERB) of Nepal Health Research Council (reg. no. 26-2017). Written consent was obtained from the participants enrolled in the study.

Consent to publish-Not applicable

Availability of data and materials- The datasets used and/or analysed during the current study are available from the corresponding author on reasonable request. 
Competing interest- None

Funding- Swedish Research Council (VR), Sweden, Laerdal Foundation for Acute Medicine, Norway and Einhorn Family Foundation, Sweden. The funders had no role in design of the study.

Authors' contribution

AKC, NT and HL conceptualized the study. NT and AKS conducted the first draft of the analysis. AKC and $\mathrm{HL}$ reviewed the statistical analysis. NT and AKS made the first draft. AKC, HL, RG and PP reviewed and revised the manuscript. All authors read and approved the final version of the manuscript.

Acknowledgement-We would like to acknowledge Shekhar Devkota in the data cleaning. Research team members and all the mothers who consented to the study. We would like to thank Nisso Nurova for reviewing the manuscript.

\section{References}

1. Collaborators GBDCM: Global, regional, national, and selected subnational levels of stillbirths, neonatal, infant, and under-5 mortality, 1980-2015: a systematic analysis for the Global Burden of Disease Study 2015. Lancet 2016, 388(10053):1725-1774.

2. Collaborators GBDMM: Global, regional, and national levels of maternal mortality, 1990-2015: a systematic analysis for the Global Burden of Disease Study 2015. Lancet 2016, 388(10053):17751812.

3. Oza S, Cousens SN, Lawn JE: Estimation of daily risk of neonatal death, including the day of birth, in 186 countries in 2013: a vital-registration and modelling-based study. Lancet Glob Health 2014, 2(11):e635-644.

4. O'Mahony F, Hofmeyr GJ, Menon V: Choice of instruments for assisted vaginal delivery. Cochrane Database Syst Rev 2010(11):CD005455.

5. Keriakos R, Sugumar S, Hilal N: Instrumental vaginal delivery-back to basics. J Obstet Gynaecol 2013, 33(8):781-786.

6. Ameh CA, Weeks AD: The role of instrumental vaginal delivery in low resource settings. BJOG 2009, 116 Suppl 1:22-25.

7. Family Health Division DoHS, Ministry of Health and Population: National Safe Motherhood And Newborn Health-Long Term Plan (2006-2017). In. Kathmandu, Nepal; 2006.

8. Family Health Division DoHS, Ministry of Health and Population: National Policy on Skilled Birth Attendants, 2006. In. Kathmandu; 2006.

9. Lurie S, Glezerman M, Baider C, Sadan O: Decision-to-delivery interval for instrumental vaginal deliveries: vacuum extraction versus forceps. Arch Gynecol Obstet 2006, 274(1):34-36.

10. Edozien LC: Towards safe practice in instrumental vaginal delivery. Best Pract Res Clin Obstet Gynaecol 2007, 21(4):639-655. 
11. Kc A, Ewald U, Basnet O, Gurung A, Pyakuryal SN, Jha BK, Bergstrom A, Eriksson L, Paudel P, Karki S et al: Effect of a scaled-up neonatal resuscitation quality improvement package on intrapartumrelated mortality in Nepal: A stepped-wedge cluster randomized controlled trial. PLoS Med 2019, 16(9):e1002900.

12. Kc A, Bergstrom A, Chaulagain D, Brunell O, Ewald U, Gurung A, Eriksson L, Litorp H, Wrammert J, Gronqvist $\mathrm{E}$ et al: Scaling up quality improvement intervention for perinatal care in Nepal (NePeriQIP); study protocol of a cluster randomised trial. BMJ Glob Health 2017, 2(3):e000497.

13. Fund UNP: Setting standards for emergency obstetric and newborn care. In. New York; 2014.

14. Bailey PE: The disappearing art of instrumental delivery: time to reverse the trend. Int J Gynaecol Obstet 2005, 91(1):89-96.

15. Li Y, Townend J, Rowe R, Knight M, Brocklehurst P, Hollowell J: The effect of maternal age and planned place of birth on intrapartum outcomes in healthy women with straightforward pregnancies: secondary analysis of the Birthplace national prospective cohort study. BMJ Open 2014, 4(1):e004026.

16. Lyndrup J, Weber T, Legarth J, Nickelsen C, Guldbaek E: Prediction of mode of delivery and 'DisFIL score' following induction of labor by local PGE2. Eur J Obstet Gynecol Reprod Bio/ 1993, 52(1):1119.

17. Hashim N, Naqvi S, Khanam M, Jafry HF: Primiparity as an intrapartum obstetric risk factor. J Pak Med Assoc 2012, 62(7):694-698.

18. Family Health Division DoHS, Ministry of Health and Population: National In-Service Training Strategy For Skilled Birth Attendants. In. Kathmandu; 2006.

19. McDonnell S, Chandraharan E: Determinants and Outcomes of Emergency Caesarean Section following Failed Instrumental Delivery: 5-Year Observational Review at a Tertiary Referral Centre in London. J Pregnancy 2015, 2015:627810.

20. Smyth RM, Alldred SK, Markham C: Amniotomy for shortening spontaneous labour. Cochrane Database Syst Rev 2007(4):CD006167.

21. Selin L, Almstrom E, Wallin G, Berg M: Use and abuse of oxytocin for augmentation of labor. Acta Obstet Gynecol Scand 2009, 88(12):1352-1357.

22. American College of $O$, Gynecologists, Society for Maternal-Fetal M, Caughey AB, Cahill AG, Guise JM, Rouse DJ: Safe prevention of the primary cesarean delivery. Am J Obstet Gynecol 2014, 210(3):179-193.

23. Milsom I, Ladfors L, Thiringer K, Niklasson A, Odeback A, Thornberg E: Influence of maternal, obstetric and fetal risk factors on the prevalence of birth asphyxia at term in a Swedish urban population. Acta Obstet Gynecol Scand 2002, 81(10):909-917.

24. Lawani LO, Anozie OB, Ezeonu PO, lyoke CA: Comparison of outcomes between operative vaginal deliveries and spontaneous vaginal deliveries in southeast Nigeria. Int J Gynaecol Obstet 2014, 125(3):206-209. 
Figures

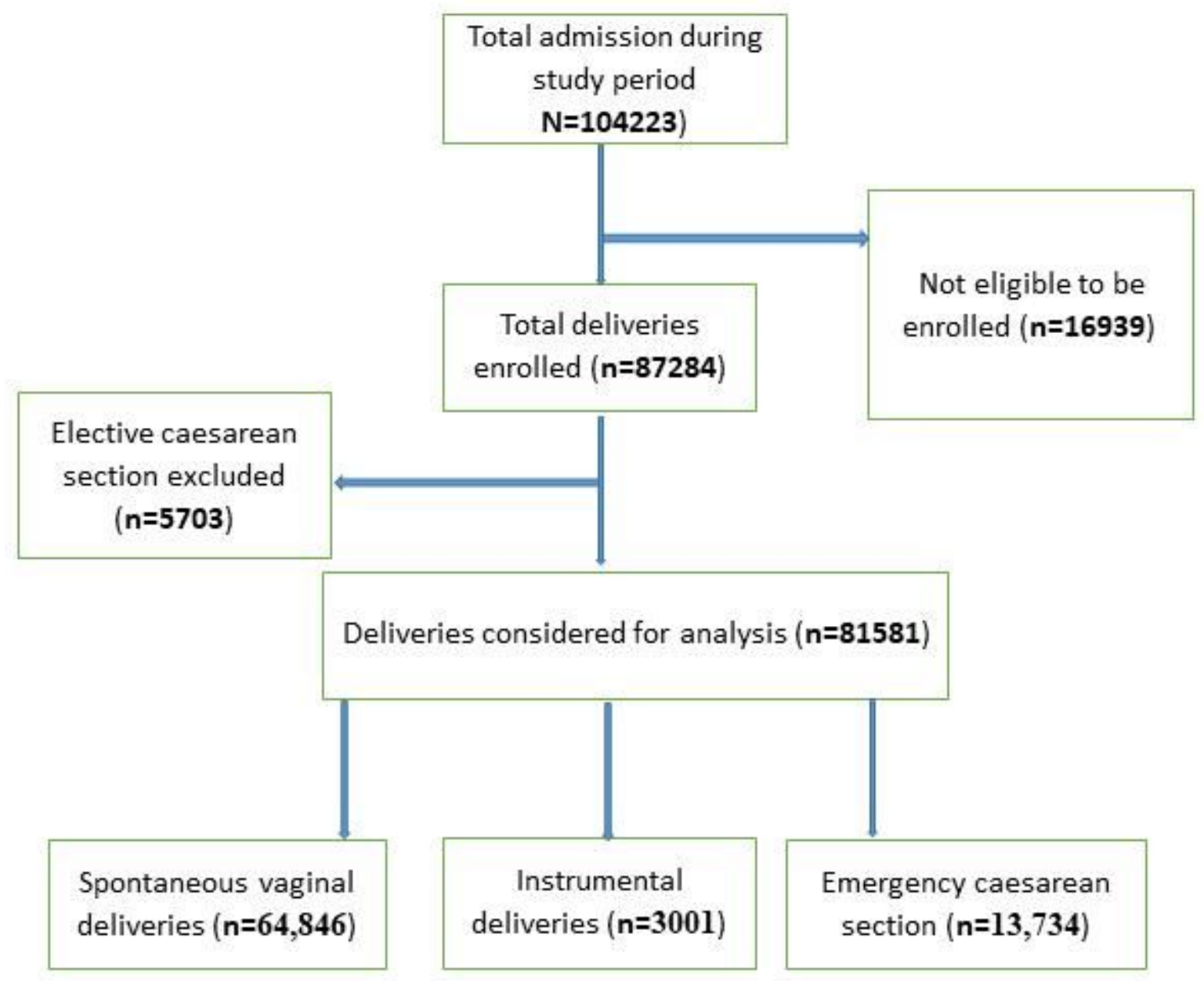

Figure 1

Study flow diagram 


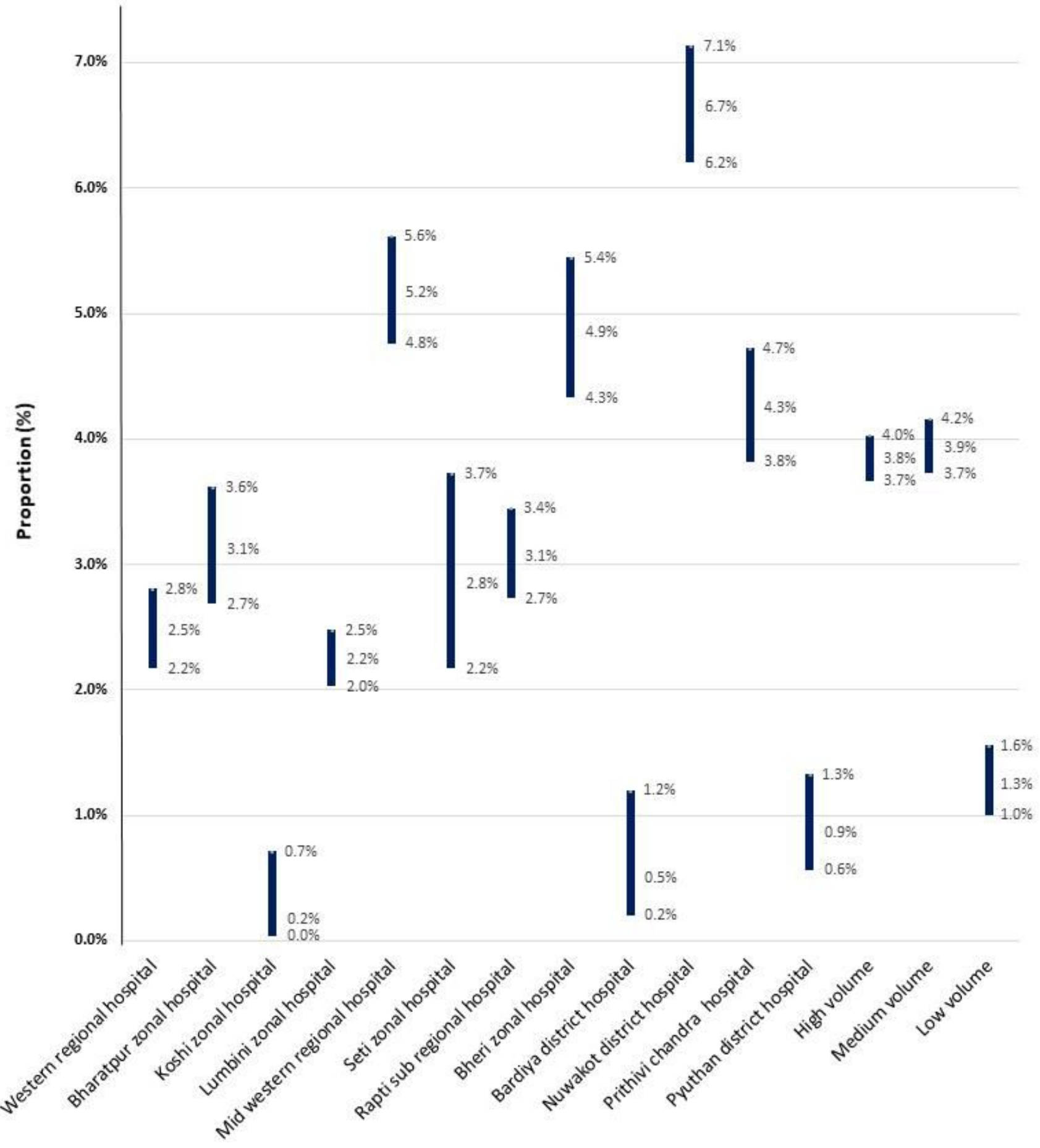

Figure 2

Rate of instrument assisted birth by hospital and volume of delivery

\section{Supplementary Files}

This is a list of supplementary files associated with this preprint. Click to download. 
- Supplementarytable.docx

Page 16/16 